\title{
14 Dialogue and transreligious understanding
}

\author{
A hermeneutical approach
}

\author{
J. R. Hustwit
}

There is no common ground from which all theology should be derived. Every theologian is thrown into the middle of things - her family, education, cultural location - and makes her way from there. Heidegger describes this universal condition as having-been-thrown-ness (Geworfenheit). Every person comes to consciousness shaped by a world that she did not create. The result is that each person is situated differently, with different pressures, questions, and projects. For some theologians, beginning with the Gospel makes the most sense, because God created humans and their experience. ${ }^{1}$ For others, beginning with human experience makes more sense because human experience created our narratives about God. I confess that the latter approach makes more sense to me. The situation into which I have been thrown has led me to several theological hypotheses. First, the sacred, whatever its form(s), is a natural presence, equitably available to all human communities. Second, a person's linguistic-cultural background binds them to a community and limits the possibilities of what they understand. Third, the scope of what a person can understand may be enlarged, especially through dialogue. Fourth, the pursuit of truth is the end, not the beginning, of dialogue. When these four hypotheses are considered together, they suggest that the only way to do theology is to do it transreligiously - to draw on the experiences of more than one religion and to follow the truth, even if it takes one beyond the limits of her home tradition.

Hermeneutics is the study of how humans interpret various objects in the world: texts, persons, actions, events, nature. Though originally applied only to legal or sacred texts, hermeneutics has been promoted to a universal scheme of human understanding. Everything is always interpreted. There is no such thing as an unambiguous and objective meaning. Theology, from my situation, appears to be a species of interpretation. At the same time, theology is a public and constructive task that aims at the production of metaphysical truth claims, salvific practices, and proper virtues. There is considerable tension between these two descriptions. As interpretative, theology is prone to disagreement. Radically particular backgrounds will lead to divergent perceptions of God, nature, and humanity. But as public and constructive, theology aims at universality. A person's theological 
conclusions are not true only in a personal sense, or for her community, but true for all persons - true full stop. In order to reconcile these divergent aspects, a theology must acknowledge its private origins and public aspirations. That journey from private to public is accomplished by a never-ending process of comparative dialogue with difference. Individuals are only able to offer a narrow selection of possible experiences. The way to avoid falling into a debilitating relativism is to compare finite human perspectives to see if they converge on any commonalities. Through collaboration, theologians may strive to combine religious interpretations into an ever more refined model of human existence, the ultimate(s), and the world.

\section{An available God}

In the spirit of the private striving for public legitimacy, I offer a few biographical anecdotes to illustrate how my own private experience has served as evidence supporting theological conclusions. At seven years old, I was living in Texas. I spent a lot of time in my head, because I was not athletically talented. Two influences competed for my attention: first, the fairly bland nondenominational Christianity taught at my new private school and second, my love for superheroes. I was not alone. Most of my classmates - it was an all-boys school - were interested in comic books, aliens, or anything that was strange. I remember there were lots of discussions involving slime, blood, claws, and laser swords.

Say what you will about parochial schools, this one was pretty tolerant of diversity. There were Jewish students who sat next to me during the mandatory chapel services. However, I ended up crossing a line that startled the normally tolerant administration. I was given an assignment. The assignment was to draw what I thought God looked like. I am pretty sure that even at seven, I had been asked to do this before. I knew that drawing an old man with a beard would be the predictable answer. And I knew that at least four other boys would draw a glowing ball of light - almost as predictable as the old man. As I racked my brain about what to draw, I suddenly had an idea. It wasn't profound, and I did not take the assignment very seriously, but I did love to draw. I put my crayon to work.

The next day my parents sat me down and told me that Sister Rachel, headmistress of the Lower School, had asked to speak with them. She was slightly concerned about my drawing of God. The large piece of manila paper had been folded into fourths to fit into my desk. They unfolded it and asked me to explain what I had drawn. It was a male torso, unreasonably muscular, with the head of a stag. I'm not sure if Sister Rachel was more concerned with my poor grasp of how many abdominal muscles humans possess or if she worried that my family were neo-pagans who honored the King of the Hunt. Honestly, if you ask a room full of seven-year-old boys to draw something they've never seen, I think you should expect some weird stuff. But my parents had promised Sister Rachel they would talk to 
me about it. So they asked me why I drew God that way, like a deer-man. I was a little bit afraid of being in trouble, but I also sensed that for my parents there would be no wrong answer, and this gave me space to give an impromptu explanation for my deer god.

I said, "If God is the God of all creation, then He is just as much nonhuman as he is human." My parents awkwardly nodded, and the picture was never mentioned again. Upon reflection, I was surprised to discover that I meant what I said. An intuition about God's universality had crystallized into what was probably my first theological conviction. The divine produces nature, of which human beings are only a small part. Of course humans would claim that they are in the image of God. My little sister also claimed to be the center of the universe, but she, I knew, was not a credible source. At age seven, the propositions "We are made in God's image" and "We make God in our image" both made sense. Even deer, in so far as they are capable, must experience the deity in their own ungulate way. And if they can imagine God, they probably imagine a being with antlers. Except for the cheeky deer who shock their parents by describing an anthropomorphic God.

As I learned about other religions, my early intuition about God's abiding presence developed. How could it be moral for God to answer the prayers of some communities and not others? If God is just, God would be equally available to all humans, or even all creatures. All creatures are equally subject to the forces of gravity and electromagnetism. All should be equally subject to the divine as well. A loving and just God would be uniformly present to all of creation, so that all have relatively equal chance of experiencing the divine relative to their species. I would describe this intuition as something like egalitarian religious naturalism. Regardless of how or when God acts in history, the presence of God is a permanent feature of the natural world - a divine piece of metaphysical furniture. And though God cannot be reliably perceived with the five senses, God is able to be experienced with diverse mystical and contemplative practices.

Now I am not sure how firmly I would hold this hypothesis today. Of the four propositions in this chapter, I hold this one with the least confidence. If pressed, I would probably add a qualification. Despite God's equitable presence to all human communities, individual persons may have clearer or more obscured perceptions of God as the result of spiritual practices or distractions. This qualification, which rejects God being closer or further with communities but grants that God may be closer or further for individuals, is itself a very modern and liberal intuition. It allows for relationship and consequences for individuals, but not for groups. Nevertheless, it seemed the most adequate model of God's presence at age 7, and still does, despite my doubts, at age 39 .

If God is natural furniture, this implies a negative corollary: God is equally mediated to human beings. That is to say, because humans are interpretation machines, God's presence is always hidden behind the perceiver's 


\section{J. R. Hustwit}

biases and expectations. And this is equally true for all humans. The Aleutian Islander is just as alienated from the true nature of God as the Ibizan. Getting God somewhat wrong is part of human nature. Theologians may be more or less optimistic about how thickly or thinly human subjectivity mediates the presence of the divine, but there are no human communities that are a priori excluded from or central to the task of theology.

\section{Word is bond}

If the divine is uniformly present to all humans, it should be the case that nearly all human beings have displayed some sort of religious sensibility. And this has more or less been the case historically. But what is really remarkable are the patterns of variation in how religious ultimates (e.g., Yahweh, Shiva, nirvana, or nirguna Brahman) are described. A survey of human beings would show that although there is no universal agreement about religious matters, there is a good deal of piecemeal consensus. Agreement concerning belief and practices clump together historically and geographically. Scholars of religion have attempted to classify these clumps into "religions," and the most common classification is that there are five large clumps: Judaism, Christianity, Islam, Hinduism, and Buddhism. There are also a number of smaller clumps: Sikhism, Jainism, Celtic Neo-Paganism, Shinto, Confucianism, etc. This convenient canon of world religions is by no means a perfect representation of human religiosity and needs to be continually interrogated and revised. Nevertheless, it does reveal an important fact about human religious experience. The way that the divine is experienced correlates to human communities. Presbyterians are not scattered across the continents in a perfectly random distribution. They emerge from a group of people who are able to share a way of life. Religious experience clumps together because communities clump together. And language is the primary clumping agent. Language emerges co-originally with a community of human beings who require a common set of signs in order to effectively communicate. But language is not just a code humans use to translate thoughts into sounds and back into thoughts again.

Every category of being that I use is language inherited from my family and community. When I entertain light, the concept is not speciated, but simple. Light is light. I can attribute adjectives to it. The light is bright. The light is pink. But I do not distinguish light into distinct kinds. However, I do make distinctions between kinds of pastry. A Chelsea roll is not just a swirly generic pastry; it is a kind of pastry with a definition that excludes kolaches and knish. Chelsea roll, kolache, and knish are completely distinct classes of objects in my mental filing system, unlike light, which does not admit any kinds. The simplicity of light and speciation of pastry is an arbitrary linguistic convention. Some may argue that sunlight is a different kind of thing than fluorescent light. A colleague once told me that my office's fluorescent lights will eventually kill me and I need incandescent bulbs. I don't think 
that way - light is light - but I can understand his worldview. Conceptual speciation, and language in general, precedes discursive thought, speech, and writing. Because it precedes even the will, many hermeneutic philosophers have noted that though human beings create language, the reverse is also true.

The influence of language upon religious experience becomes apparent when I reflect upon my early experiences in the church. Like many adolescent Methodists, I was sent to summer church camps, where I would cultivate a close relationship with the Almighty. In my experience, church camp was a week-long exercise in channeling hormones into a fervent piety. Everything was emotionally intense: the awkwardness of living with strangers, the ritualized behavior at mealtimes, and evening devotionals held at night on the top of a hill. One night, at the end of the week, I remember being instructed to pray to God - or Jesus. Honestly, it was never entirely clear to me to whom I should pray. But pray I did. I asked God, if $\mathrm{He}^{2}$ existed, to show me an unmistakable sign. As I prayed, the sky lit up with flashes of lightning, right on cue. There were no storms - this would have been described as "heat lightning." But the timing was unmistakable. I prayed, and the lightning flashed. God was listening. I was certain.

Even though this event relied on acts of nature, it was human language that made this religious experience possible. What counts as a sign from God are culturally transmitted criteria. There is certainly a natural spectacle to lightning: it is vast, above, bright, intense, fleeting. But these traits are meaningless without a history of association. The shopping mall parking lot seems vast, the ceiling fan is above, the sun is bright, vinegar is intense, and birthdays are fleeting. None of these objects signify the divine in my home clumps. Conversely, it would be absurd for me, given my clumps, to find a sign from God in an unusually quiet toilet flush or a surprisingly stale donut in an unopened package. Toilets and stale food do not have a history of association with God in the texts of Christianity, nor more immediately in the popular culture of my childhood. Scripture, novels, television shows, and comic books all repeat certain linguistic signs: the lightning bolt is divine, a tool of the sky father, weapon of Zeus and Thor. But it is possible to imagine a culture that had a different tradition in which the stories surrounding the divine involved the silencing of troubled waters. For that culture, a quiet faucet, or even a flush might signify the presence of the sacred.

My intention is not to reduce all religious experience to cultural projection. But rather to point out that whatever religious experience humans can understand is always clothed in language. I do believe there is a real nonhuman component to many types of religious experience, because that is the most plausible explanation for the amount of similarity between religious experiences. But if there are any naked undigested alien epiphanies, they do not last for long. Our brains do not work that way. As experience comes to consciousness, it is interpreted into linguistic concepts and categories. Untangling the contributions of the divine from the contributions 


\section{J. R. Hustwit}

of human culture is tricky business. How much is authentic revelation and how much is contributed by my own preunderstanding? Is it 50/50? 20/80? I do not think there is an easy or certain way to determine that. Nevertheless, I continue to search for the presence of the sacred behind the cliché of the lightning.

I struggle with discerning the purity of religious experience. Our inability to step outside of our own perspective to see the matter "objectively" is precisely why interreligious dialogue is necessary. We may be too embedded in our own experience to judge the authenticity of our own experiences, but by having authentic dialogue with persons embedded in different traditions, we may detect patterns amid the interference, signal amid the noise. But authentic dialogue is not as it easy as some may assume. Communication within a clump of common meaning encounters fewer incidents of problematic meaning, but understanding between clumps is problematic. Because I was raised to look for lightning, I will not notice when the toilet is quiet.

\section{In defense of appropriation}

So far, I have given a few experiences that support my own hypotheses for the basic theological situation of human beings. First, the sacred is, on the whole, equally available to all humans. Second, all persons experience the sacred in terms of a finite linguistic community, and this finitude routinely causes conflicts of interpretation both in and among communities. These first two hypotheses have several implications. If the sacred is equally present and equally mediated to all cultures, more than one religious tradition may disclose truth (propositional or salvific) despite incompatibilities of doctrine and practice among them. This is not to say that all religious traditions are equally good, or even partially good. It is perfectly possible that an entirely bogus religion may arise and perpetuate into an enduring tradition. Bogus religions aside, some theological claims are truer than others. Some are more fruitful or coherent. Interreligious dialogue is that process that allows theologians to make comparative judgments about religions. But in order for this to happen, for transreligious theology to get its legs, humans must be able to expand the horizons that constrain possible meaning. Every person only sees the divine through the lens of her cultural categories, but that lens can be polished, enlarged, and bent by talking with others. A third hypothesis is necessary: one's worldview is not set at birth or at some later point in childhood. The lens changing occurs through an ongoing process called appropriation. This is not a controversial hypothesis. People learn new things every day. But some learning simply combines elements of a worldview in a new way, and some learning introduces genuine novelty into the worldview. Theologians are able to understand new and other religions because they are able to appropriate novel ideas and practices and make them relevant to their own situations. 
School, ideally, should provide many easy examples of appropriation. Having left the private boys' school for a public high school, I was fortunate to participate in a humanities curriculum, which combined history, art, literature, and philosophy into a single course that lasted two years and covered Europe from the sixth century BCE to the present. During the ancient Greek unit, the class was divided into five or six polises, and we were encouraged to adopt the culture of the polis and stay in character. Our research was fairly shallow, so for us, this meant that the Spartans knocked down everyone else's temples and the Corinthians pretended to drink a lot. Because the role playing was immersive, we were not learning history at one time, then doing art at a later time. The subjects were all mixed together because life in ancient Greece was all mixed together. It slowly dawned on me that the practice of learning subjects in isolation from each other was at odds with the natural state of things. Art does not exist in isolation from science, and neither is immune to politics. This caused a relatively drastic transformations in my conceptual categories. My worldview had been one that had received the school disciplines uncritically (i.e., as unrelated skills to facilitate a future career). Suddenly, there was a problem reconciling those distinct disciplines with the newly perceived messiness of the world. From then on, every course seemed to me like a compromised endeavor - a failure to mirror the real world.

Though this class was not what anyone would typically think of as interreligious dialogue, it was structurally the same. I experienced a new way of dividing the world of experiences, which was gradually adopted. This was not a revelatory bolt, but a process of comparing my new insight, "world resists disciplinarity," with a previous assumption, "world facilitated by disciplinarity." I had appropriated something from my teachers, and it had caused discomfort, followed by an appropriation of a new idea. Phenomenologically, appropriation is an oscillation between my own horizon and the alterity of the object of interpretation. Philosopher Paul Ricoeur describes it as a three-part cycle of guessing, validation, and then comprehension (Ricoeur 1976, 75-88). And the process of guess-validation-comprehension repeats. Endlessly. A new meaning of the world - "world resists disciplinarity" - was guessed, then tested for coherence with the text (i.e., the structure of the course I was taking). Once the differences between my own worldview and the alterity of the text had been negotiated, I understood the text as applicable to my world. I did not assent to "world resists disciplinarity" as a sterile fact, but as a quality of the world in which I make plans and love things. In order for something to be understood, it must matter to the person. For this reason, Heidegger describes the world of our experience as characterized by my-own-most-ness (Jemeinigkeit). We are only aware of a thing when it serves a purpose for us.

And because hermeneutics is cyclical, I was not done with the notion of disciplinarity resistance. Later experiences would cause me to re-examine it and adjust its application to my own-most world. As a university student, 
I had been assigned the Dao De Jing. I confess to not reading much of it, but I did notice its argument against formal education. Take, for example, Chapter 32:

The Way is forever nameless.

Unhewn wood is insignificant, yet no one in the world can master it ... When unhewn wood is carved up, then there are names.

Now that there are names, know enough to stop!

To know when to stop is how to stay out of danger.

(Ivanhoe and Van Norden 2011, $32,178-179)$

Unhewn wood, representing the cosmos as it truly is (i.e., uncomplicated by distinctions), is here contrasted with human conceptualizations. Such concepts, which formal education reinforces, inevitably chop up the wholeness of the Dao. The result is distorted thinking and, the Dao De Jing argues, human misery. My own appropriation of this text was based on the previous understanding of disciplinarity resistance from my earlier humanities course. Ah-ha! The Dao De Jing is saying something similar to what I had already understood. "Names" are like "disciplines." "Unhewn wood" is like "life outside of the classroom." There is a similarity-in-difference. In that respect, appropriation is thoroughly metaphorical. When we appropriate a term, we use similarities to analogize the foreign to our own experience, while maintaining a tension with the differences. The goal is to suss out the interaction between resemblance and difference. The similarities are the vehicle that smuggles content into my horizon, and the differences explode its boundaries, enlarging the possibilities I may imagine.

The word "appropriation" is frequently criticized in discussion of cultural appropriation. When a person adopts the fashion or customs of another culture without sufficient understanding of the meaning, we argue that they do violence to the culture by appropriating it. But in these cases, we should say that the insensitive person has malappropriated the custom. For all understanding is appropriation, and it can be done skillfully or clumsily. The term "appropriation" ought to be rehabilitated, much as Gadamer sought to rehabilitate the term "prejudice" (Vorurteil; Gadamer 2000, 277-306). Appropriation itself is inescapable and only a vice if we fail to validate the meaning we have guessed against the structure of the text. We cannot complacently assume that we have correctly guessed the meaning of another religion when we see the first resemblance.

It is crucial for me, as a Christian, to note that the Dao De Jing's idea of nature is quite different from what I may imagine. Likewise, the Dao De Jing's claims about human nature and the ability of the mind to perceive the world probably differ from mine. All of these points of difference must be maintained along with the similarities. If I neglect the differences between religions, I assimilate the other religion into my own. If I neglect the 
similarities between religions, I am unable to comprehend anything unfamiliar. But if we grant that our worldview is changeable, then we have the ability to expand it to appropriate other religions. Healthy appropriation is always in danger of collapsing into assimilation or exoticization, but if the sacred is disclosed in other religions, it is worth our while. Understanding other religions is required to live together in peace, but also required to judge truth claims as "better" and "worse" hypotheses.

\section{Truth deferred}

Not everybody loves to argue. I have been slow to come to this realization. I love to argue. I love to be right. I sometimes spend too much time trying to poke holes in the arguments of others. There are a couple of culturallinguistic facts that could explain why I tend to behave this way. The most immediate cause is probably the years studying for a philosophy degree, which enculturated me to focus on argumentation and logic. I was taught that philosophy is mostly a critical task and rarely constructive. Philosophy courses, until the advanced stages of the degree, present a text to the student, ask the student to distill an argument from the prose, and then require the student to criticize the argument. After so many years, this training leads to a particularly critical temperament - a tendency to look for the weaknesses of things first. My classmates and I were great at tearing things down, but not very good at building things on our own. Although critical analysis is an essential skill, it is not the only skill worth developing.

But why is philosophy taught this way? Without going into an elaborate intellectual history, I think Christian theology deserves much of the blame for why I am no fun at parties. Christianity has always placed an emphasis on orthodoxy, or correct belief. Believing certain propositions to be true and others false has the chief criterion for determining Christian identity and value. The first seven ecumenical councils of the Christian church are striking examples. A tremendous amount of time and mental energy went into deciding exactly which propositional truth claims should be endorsed and which should be condemned as heresy. It is no coincidence that Christian theology has historically focused on doctrine much more than practice, dialogue, or affect. So, the Christian theology that dominated the medieval university as "queen of the sciences" ${ }^{3}$ passed on its preoccupation with propositional truth claims to the teaching of philosophy, first in Europe and then its colonies. So even for those philosophers today who consider themselves to be completely divorced from Christian belief and practice, Christianity has shaped their academic discipline, their cognitive training, and thus their temperament. And that is one reason why they - and I - argue too much.

With this temperament as a liability, I took a job teaching religion at a small university in the American South, and with encouragement from the administration, began an interreligious club for students. This was 
challenging. Though our student population contains a relatively high proportion of international students, our domestic students tend to be fairly sheltered and uncurious. The result was a lot of potential for expanded horizons for those who participated and a lot of resistance to those programs from those who would not participate.

My first attempts at getting college students to sit together and talk were based on my idealized vision of what interreligious dialogue should be: a round table of persons steeped in their own traditions, arguing over metaphysical claims in good cheer until everyone agreed about the nature of reality. I invited a number of students to gather over some pizza and threw down some of my most combustible debate kindling: "Is the sacred personal or nonpersonal?" "Is the universe infinite or discretely bounded?" Nothing. Awkward silence. Polite thanks for the pizza and excuses to be somewhere else.

My vision of interreligious dialogue could not have been further from how dialogue - on any topic - actually begins. My students are not steeped in their own traditions, much less anyone else's. They frequently come from secular families, and when they do have a background in religious participation, they are hesitant to speak for their tradition. Even if they were informed and willing, they would not be interested in doing so. My own project of transreligious theology does not matter to my students. What they do value highly (besides food) is relationships. Ultimately, I found that if I organized a social event, like a halal potluck during Eid al Adha, attendance was much higher. By the end of the school year, after a series of well-attended social events, the students had organized their own small interreligious discussion group in the evenings.

I think that in the situation of interreligious dialogue, whether one's dialogue partner is a human, a written text, or some other symbol, care precedes knowledge. ${ }^{4}$ That is to say, human beings cannot understand a thing unless it first has a place in their own-most concerns. This is why it is a mistake to begin interreligious dialogue with a contest of truth claims. Truth-directed inquiry requires concern, which manifests as goodwill, openmindedness, and curiosity about other religions. Dialogue does not require its participants to agree beforehand, share a worldview, or even like each other. But it does require an openness to the legitimacy of the other and an interest in the message of the other. Dialogue begins with a mutual recognition of humanity and only later takes up competing truth claims.

Of course, we may find ourselves in a contest of truth claims with someone we have just met, with no established relationship. But even when we argue with strangers about religion, this is not a case of truth questions preceding relationship. Rather, the stranger is assigned a relationship status as the argument commences. This status may have been assigned even before the stranger appeared. We may have an imaginary adversary in some matter, and we project it on to the person before us. It is precisely because there has 
been so little time for the relationship with the stranger to develop that these encounters usually end unhappily.

My experience with students and student organizations has moderated my hard-nosed philosophical instincts and taught me that relationships of some kind are necessary before arguments can be entertained. Practically speaking, the truth is a concern for advanced stages of dialogue. Philosophically speaking, the truth should be a heuristic device. It guides and regulates the process of dialogue even if it is never permanently achieved. For no matter how firm my conviction, there is always another dialogue partner around the corner.

\section{Conclusion}

So, I am left with four theological hypotheses: 1) The Ultimate is equally available and equally mediated to all humans. 2) This mediation is largely due to the conceptual schemes that emerge from communities of humans. 3 ) Human conceptual schemes are routinely enlarged or transformed through the act of appropriation, which is a species of interpretation. Finally, 4) the adjudication of truth claims submits to the demands of an existential relationship and not vice versa. Taken together, the claims suggest to me an infinitely long process for theology. It is almost Hegelian. We should engage the other - person or text - in interreligious dialogue. The dialogue is usually productive. It produces an enlarged horizon, a new synthesis, which then is brought into the next dialogue. But unlike Hegel, this process does not unfold according to the logic of Absolute Spirit. Instead, it traces the boundary that joins human language and the prelinguistic sacred. There is a pessimistic interpretation of transreligious dialogue, that while it may foster goodwill among religious communities, it is a metaphysical goose chase. However, there is an eschatological hope that it is more than that. As we perpetually dialogue with otherness, we trace an ever more complete model of the world.

\section{Notes}

1 Experience should be understood widely, not as just experience gained through the five sense organs. Theology employs a wider range of experience than just the five senses. Ethical intuitions, aesthetic sensibilities, emotive states, and recognition of authority are also modes of perception, though more susceptible to idiosyncratic interpretation than the five senses.

2 In the language of my church community, the masculine pronoun was always used to refer to the divine. This set up my own uncritical expectation of God's masculinity. In fact, I remember imagining that God probably looked a lot like my grandfather: dark oily hair, olive skin, a large nose, and pale yellow golf shirt with a chest pocket. The shirt was by far the most vivid part of the image.

3 Here, science is defined broadly. It is derived from the German Wissenschaft, which is perhaps better translated as a method of production of knowledge. 


\section{J. R. Hustwit}

4 This insight is present throughout the hermeneutic tradition, but is most clearly articulated by Heidgger. Care (Sorge) is the fundamental mode of being in the world. Metaphysical truth claims are but one species of existential concern.

\section{References}

Gadamer, Hans-Georg. 2000. Truth and Method. trans and edited by Joel Weinsheimer. 2nd rev. ed. New York: Continuum.

Ivanhoe, Philip J., and Bryan W. Van Norden, eds. 2011. Readings in Classical Chinese Philosophy. 2nd ed. Indianapolis: Hackett Publishing.

Ricoeur, Paul. 1976. Interpretation Theory: Discourse and the Surplus of Meaning. Fort Worth, TX: Texas Christian University Press. 